Kellner, the kathode being a layer of mercury at the bottom of the bath. On the current being passed, the potassium liberated at the kathode dissolves in it, forming an analgam, which as it is formed is drawn off and run into pure water, the water being decomposed, assisted by an auxiliary current, with evolution of hydrogen and formation of caustic potash, which is obtained in the pure condition by evaporation. Carbonate of potash may be prepared by passing a stream of carbonic acid gas into the caustic liquors before evaporation. In commerce, naturally, it is more general to electrolyse the cheaper sodium chloride, at any rate, in this country. Strontium and barium chlorate are also manufactured by electrolysis of their chlorides.

It has been found possible to prepare painters' colours by electrolysis, e.g. "white lead" is obtained in a very pure condition by electrolysing a dilute solution of sodium chlorate and carbonate, the electrodes being of lead. If the sodium carbonate is replaced by sodium chromate, a neutral lead chromate is produced, an acid chromate being formed by cautious addition of a solution of chromic acid during the electrolysis.

To attempt to mention, much less to describe, the enormous number of inorganic compounds and elements which have been prepared or isolated by the aid of electricity, would be, in an article such as this, impossible; but sufficient examples have been given to show the importance of electrical processes in this branch of chemistry.

Turning now to organic chemistry, we notice that, although a vast amount of work has been done, it is more of theoretica interest than of technical value. But now that the initial difficulties have been to a large extent overcome, and the manner in which the reactions take place is better understood, it is probable that shortly this branch of manufacturing chemistry will also undergo a revolution in the hand of the electro-chemist. As a means of synthesis and of proving the formula of substances, electrolysis has been, and is, of great value to the organic chemist. Thus on electrolysing a solution of an alkaline acetate, thane is produced; whereas by employment of a succinate, ethylene is formed, a solution of fumaric acid yielding acetylene. These are, of course, simple cases ; but even that seemingly unsolvable problem, the constitution of camphoric acid, has been attacked by Walker, and by means of electrolysis of it and its derivatives he has obtained results which must be of great value in ultimately deciding what is the correct formula for this substance.

Iodoform can now be produced in a state of great purity by electrolysing a solution of potassium iodide and sodium carbonate to which alcohol has been added. On electrolysis, employing electrodes of platinum, iodine is continually set free at the anode, and coming in contact with the alcohol at the moment of its liberation produces iodoform. As the reaction proceeds some of the iodine becomes converted into hydriodic acid, and this combines with the alkali liberated at the kathode, or which has been added to the bath, potassium iodide being regenerated, which by the further passage of the current is again split up. The process is a continuous one, the iodoform being from time to time removed and a further quantity of alcohol, potassium iodide and sodium carbonate added. It is interesting to note that the alcohol cannot be replaced by acetone, as in this case only a very small quantity of iodoform is produced. Chloroform and bromoform have not been successfully prepared by this method. Chloral can, however, be produced by electrolysis of a solution of potassium chloride at $100^{\circ}$, to which alcohol is from time to time added.

By the electrolysis of nitrobenzene in a strongly acid alcoholic solution, aniline is produced. If the nitrobenzene is suspended in concentrated hydrochloric acid, ortho- and para-chloraniline are formed. By electrolysis under other conditions, azobenzene, hydrazobenzene or azoxybenzene are obtained.

By the electrolytic oxidation of aniline, dye products can be obtained the nature of which depends upon the solution em. ployed, the strength of the current and the material of the electrode, e.g. if an aqueous solution of aniline hydrochloride, which may be either acidified with sulphuric acid or be practically neutral, is electrolysed, platinum electrodes being employed, a green precipitate is produced at the anode, which becomes violet, bluish-violet and finally almost black, practically the theoretical quantity of aniline black having been formed. If the aniline contain toluidine, then mauveaniline, rosaniline, $\& c .$, are produced.

Attempts have been made to obtain alizarine by electrolysis of anthraquinone in strong alkaline solution; indeed, small quantities are said to have been obtained.
It has even been found possible to utilise electricity in the dyeing of cloth. When, e.g. a piece of cloth is soaked in a solution of aniline sulphate and placed between two metal plates, which are connected with opposite ends of a dynamo, and the current passed, the aniline sulphate is converted into aniline black ; indeed, by altering the strength of the solution and the density of the current, shades varying from green to deepest black can be produced.

In the case of indigo the cloth is thoroughly impregnated with a thin paste of indigo-blue and caustic alkali; it is then placed between two metal electrodes. On the current being passed, the insoluble indigo-blue is converted by reduction into the soluble indigo-white, which on exposing the cloth to the action of air becomes again oxidised and the material dyed blue. Patterns may be printed on the cloth by cutting or stamping the plates in relief, or by connecting one pole to a metal plate and the other to a metallic pencil, when patterns, \&c., can be readily sketched upon the material (Groppelsroeder).

Such processes as have been described in these articles appear, when seen in print, as extremely simple. Theoretically they may be so; but in practice, the carrying out of these seemingly simple operations is often attended by great difficulties. For example, the temperature must not be allowed to rise too high or fall too low. The quantity of current and its potential require often to be kept within extremely narrow limits, as the following simple example illustrates.

Silver and copper can be separated by means of electrolysis, the silver alone being deposited if a very low current density ('10 ampere) is employed, whereas with a higher density ( $50-$ I 0 ampere) the copper is deposited. Naturally, then, if at the commencement of the operation the higher current density is employed, both metals will be deposited together. Many of the difficulties to be overcome are to a large extent engineering. And it is to a considerable extent due to collaboration of chemis $\mathrm{s}$ and engineers that the science of electro.chemistry has become what it is.

Electro-chemistry is quite in its childhood, but it is making marvellous and rapid progress. Works dealing with technical chemistry but a few years old require to be revised, owing to the alterations which this branch of chemical industry has brought about.

It is humiliating to realise that in this country there is hardly a book on the subject to be obtained, and in most cases even these are only transiations from Continental works. And it is to be feared that unless this branch of chemistry becomes more studied than it has been up to the present, we shall find in the near future that electro-chemistry, both theoretical and practicai, is the property of America and the Continent.

F. Mollwo PERKin.

\section{ROAD LOCOMOTION.}

THE author commenced by saying that the subject of mechanical propulsion upon common roads had now reached a point when it deserves the very careful consideration of mechanical engineers.

For many years the uses and importance of the traction engine have become more and more recognised, but its work covers only a portion of the field for mechanical propulsion on roads, and he went on to consider what has led to a general revival of a movement for lighter road-locomotives which about seventy years ago, in the days of Hancock and Gurney, reached a point that for a time appeared to be leading to permanent results of the most important kind, but which ended in com plete failure. In one sense this revival is undoubtedly due to the passing of the Locomotives on Highways Act in IS96, previous to which, for more than twenty years, a law had existed which made it impossible for any self-propelled vehicle to proceed at a rate of more than four miles an hour. The immediate cause of the passing of this Act was the attention aroused in this country by the successful introduction of the motor vehicle for purposes of pleasure in France. The real causes of the present movement were probably to be traced to the gradual feeling amongst all classes of the community that modes of transport, both for purposes of pleasure and business, on the roads had not kept pace, or indeed had made little progress at all, compared with the great changes which had been effected

1 Abstract of a paper read before the Institution of Mechanical Engineers by Prof. Hele-Shaw, F.R S., April 26 
in speed, comfort and convenience, in the direction of locomotion by rail.

The author went on to consider at some length the question of the conveyance of goods, and by means of a graphical diagram showed that up to forty miles motor vehicles, owing to the terminal charges, might compete with railways. The hygienic question and growing difficulties of traffic in large cities was next touched upon. Next the difficulties of the problem were considered, and it was shown that these difficulties were very great; and so far from the success of the railway system being an argument in favour of the immediate development of locomotion by road, the conditions of the problem were such as to involve improvement exactly in the opposite direction to that in which the railway locomotive has been successfully developed.

No doubt the progress of invention would enable a greater amount of power from a given weight of motor to be obtained but the surface to be moved over, which is the real difficulty of the road locomotive, would remain the chief factor of the problem.

The first section of the paper was therefore devoted to the mechanical problem of the behaviour of the wheel upon the road, and the progress which has been made in this direction.

Under this head the whole question of resistance upon the road was treated, and the author made a strong point of the fact that there was very little data available for determining resistance upon roads at the high speeds now permissible, and with different kinds of tyres now in use. He gave diagrams of horsepower curves of resistance adapted to English measures from the "Tableaux Numerique et Graphique" of MM. Boramé and Julien, and a series of graphical results taken with the Viagraph of Mr. Brown, showing the nature of the shocks to a vehicle by roads of macadam, stone, asphalte and wood.

The subject of pneumatic tyres was then discussed, and also the question of wheels suitable for heavy traffic, and illustrations of a number of improved types of wheels for this purpose, which had been invented during the last year or so, were given. With any existing system in which four wheels are used, it was shown that the problem of road locomotion was difficult because of the concentration of the load upon such a limited area of support. Even for heavy traffic the pneumatic tyre might come into use in the future as it extends the area of resistence by yielding, so that the surface in contact is much greater than in the case of an iron-rimmed wheel, especially when running over stone sets or hard ground.

Beyond this, it is quite conceivable that, just as in railways the number of wheels has been largely increased until a modern bogie carriage has commonly twelve wheels supporting it, it may be found economical to support a motor vehicle also upon a much greater number than at present.

The steering of motor vehicles, which was the subject of the next section of the paper, is evidently a very important part in their design, and it may at once be said that with one or two exceptions the great majority of motor vehicles are steered upon the principle which was invented by Ackermann as long ago as 18 18. The essential principle of the Ackermann system consists in replacing the pivoted fore carriage of an ordinary vehicle which has one axle for the two wheels, by two short pivoted axles each carrying one of the steering wheels. The conditions of correct running of the wheels are that when their plane is turned, their normals intersect on a point on the line of the axles of the driving wheels. The paper then went on to describe the various modifications of the Ackermann system.

The next section of the paper was devoted to a consideration of motive power and its transmission to the wheels, and under this head the particular uses and advantages of oil, steam and electricity were considered; although these various agencies have at the present moment fairly well recognised spheres of operation this must be by no means regarded as the final condition of things, or as giving a limitation to the employment of each of these types of motive power. Thus, although at present oil-engines are used for light motor vehicles and steam for heavy traffic, there are very ingenious steam motor-cars both in this country and abroad, while light oil-engines have been applied in France and also in this country in connection with heavy traffic.

Oil-engines, or internal-combustion engines, have by a process of the survival of the fittest been found so far best suited for light motors and pleasure vehicles. The cycle of the gasengine is really complex, but these motors have been brought to a high state of perfection, so that upon being started they are found to work for long distances without any attention. If really well designed and constructed, and used with a moderate amount of care, they need little repairs or adjustment, while the objection of smell, vibration, and danger from the use of light petroleum spirit with a low flash point, have all been much reduced, while each year sees an increasing number of places in town and country where petroleum spirit can be obtained. Still the objections above-mentioned must be admitted to exist, and this, together with the great expense of pleasure vehicles, has to a certain extent hitherto prevented their introduction becoming general. Again, an oil-engine, which has little elasticity in regard to an increased demand for power when ascending a hill, requires elaborate gearing for change of speed, which may be after a time, if not at first when the car is new, a very noisy and objectionable feature. Heavy-oil engines for internal combustion have been tried for motor vehicles, but the difficulties of starting and smell have not yet been satisfactorily overcome.

Steam, or external-combustion motors, require not only a generator or boiler, but also a condenser, in addition to the steam-engine itself. The latter is not used with all motors, but in winter the cloud of steam which must be visible in damp cold weather at a little distance from the exhaust, even if the steam is superheated, really contravenes the Act, which states, "No smoke or visible vapour must be emitted, except from any temporary or accidental cause." Steam introduces a more com. plicated array of pipes and fittings, and requires more attention and skill in working, but it is highly probable that such improvements will be made in connection with steam motors, that no skilled attendant will be necessary. There is already at least one steam system which is entirely automatic, whilst others are to a great extent so. It is not too early to speak as to the practical and commercial success of any of the systems using steam, but if a condensing steam-engine, automatic in action, with a boiler which is perfectly safe from any fear of explosion, can be produced, it may safely be predicted that there is a great future before it, both for light and heavy traffic, as it would have the advantages of great power and elasticity, freedom from smell, and if using heavy oil, or even coal or coke, would be free from the danger and trouble incidental on the employment of light oil, especially abroad. Moreover, the ease with which a steam motor can be started and stopped, and more particularly reversed, cannot be over-estimated.

Fuels, other than coal, coke or oil, have been the matter of careful consideration by motor-car designers. The most promising of these is acetylene, which, as derived from calcium carbide, enables a much greater quantity of energy to be obtained from a given weight of fuel ; but although it only requires one-fourth of the weight of calcium carbide to produce a given amount of work as compared with coke, the expense at present makes its use commercially impossible.

Electrical motors are clean, extremely convenient and simple, free from all vibration and danger and altogether an ideal type of motor. The limitations in the use of electricity are, however, very serious, and are discussed later in the paper.

The details of internal combustion motors are discussed under the six headings upon which their success more or less depends, viz. : (1) carburisation, (2) ignition, (3) starting, (4) governing, (5) balancing, and (6) cooling.

The subject of steam is then treated at considerable length, and types of the more important steam heavy motor vehicles, such as those of Thorneycroft, Simpson and Bodman, Musker, Coulthard, Bayley and Clarkson and Capel are given, together with various examples of water-tube and flash boilers, which may be said to be the two types of boilers specially suitable for motor vehicles on account of their high steaming capacity in proportion to their small weight.

In considering the actual results which have been obtained by motor vehicles, a distinction is made between pleasure vehicles and those for the conveyance of goods. For the formex, the actual cost of working is not by any means the first consideration in a large number of cases, in fact, the cost is comparatively of small importance. Questions of comfort, durability and safety, as well as freedom from liability to break down, are the chief points to be considered. These matters can scarcely be summed up except as the result of lengthy experience, and now undoubtedly that experience is gradually being acquired.

When we come to the question of goods traffic, the matter is of course entirely one of cost, including not merely the outlay, working and upkeep, but deterioration, which in road vehicles is exceptionally heavy. Extended trials of actual working are necessary for any final opinion of the relative merits of different types of heavy motor vehicles, and the author has fortunately

NO, I 597 , VOL. 62 ] 
been able to secure much valuable testimony of this sort on the subject.

A great deal, however, can be ascertained by careful trials, such as those which have been undertaken on two occasions at Liverpool (1898 and r899), since measurements and data can be obtained with a staff of observers for a limited period, which could scarcely be secured in continuous working. The results of these trials are given in tables and also statements by the Chief Mechanical Engineer of the Lancashire and Yorkshire Railway, on the working of a Thornycroft motor wagon; the Engineer-in.Chief, Mersey Docks and Harbour Board ; and the City Engineer of Liverpool, on the working of Leyland motor wagons; and by Mr. Bryan Donkin, on the tests of motor carriages at Richmond and Birmingham.

Looking at the whole question, it may be safely said that the motor vehicle has come to stay, and that its uses, both in peace and war, will rapidly and enormously develop. The public interest which is now seen partly by the immense number of patents taken out in connection with the industry, partly by the great growth of literature on the subject, and by the formation of automotor clubs, is not a mere transient thing, and although the motor vehicle is at present still somewhat of a rara avis upon our roads, it may not be going too far to think that the coming century will see a development of locomotion upon roads comparable with the development of locomotion of the :ailway in the century which, according to our individual views of chronology, is either past or so very nearly past.

\section{THE UNIVERSITY OF BIRMINGHAM.}

THE present position of the scheme for the establishment of a Midland University was explained by $\mathrm{Mr}$. Chamberlain, Chancellor of the new University, at the first meeting of the Court of Governors, held on Thursday last. In the course of his remarks, Mr. Chamberlain is reported by the Times to have said that it was desired to create a great teaching University, in which all who came to them for it should find efficient and complete instruction in every branch of knowledge. Again, they desired that their University should be a school of research. They were firmly convinced that that was necessary if it was to maintain its dignity and great position. They believed that those were the best teachers who were themselves constantly learning, and that without adding continuously to the common stock of knowledge they would not be fulfilling their duties. In order to secure those objects they ventured to ask for a further endowment of a quarter of a million sterling. To-day they were able to announce that they had already received promises of $330,000 l$., the amount having been largely increased by the munificent donations of Mr. Carnegie, of an anonymous benefactor, of Mr. Charles Solcroft, and of Mr. George Kenrick.

They intended that their University should be a distinctive University. In what he had hitherto indicated there was nothing original, nothing in which they were likely to specially differentiate themselves from the other great Universities, especially from the modern Universities in this country and the older Universities of Scotland; but they hoped that their University would take some colour from its environment, that not only would it be a school of general culture, but that it would also practically assist the prosperity and welfare of the district in which it was situated by the exceptional attention which it would give to the teaching of science in connection with its application to local industries and manufactures; and this portion of their task had turned out to be much greater, much more responsible, than they anticipated. They were encouraged in undertaking it by the gift of $\mathrm{Mr}$. Carnegie, which was specially to be devoted to the creation of a college of science, following somewhat the example which had been set by the great colleges in the United States of America; and Mr. Carnegie followed this up by a proposal that a deputation from the intended University should visit the chief seats of learning across the water.

Those who had read the report of the committee that had visited Canada and the United States would begin to understand how it was that we were behindhand in the preparation for that great struggle which must come, that commercial competition between nations in which the weakest would inevitably go to the wall. For what did they find established both in the United States and in our own colony of Canada? They found great institutions connected with a general University, with colleges of science occupying large spaces, in which the area NO. I 597, VOL. 62 , was counted by many acres, fully equipped with proper buildings, with the most modern and complete machinery, with the latest scientific appliances, with laboratories for every conceivable scientific purpose ; and in those great colleges a training was given such as they desired to see imitated in this countrya training based, as all education ought to be, upon a foundation of general culture, but specialised in its course, highly specialised according to particular and separate work which each student intended to undertake in life. As a result of this they began to see how it was that in America the great commercial and industrial undertakings, the manufacturers and inventors, found no difficulty whatever in obtaining the services of as many young men as they might require to manage and complete and develop their undertakings, all of them ready when they left college, not merely to deal with the ordinary routine and management of a business, but to bring to it the latest discoveries and to apply the highest science to its development. That was what they wanted in Birmingham, and they would not have the University which they all had in their minds until they had accomplished it.

All that was wanted was money. The committee had pointed out that to carry out this scheme with any completeness a further sum, partly for endowment, partly for buildings and machinery and appliances, of $155,000 l$. was required. He was quite convinced, even from an incomplete examination of the project, that they had under-estimated the cost. He thought himself that another quarter of a million was the smallest sum which they would require in order to put this portion of their undertaking upon a thoroughly satisfactory basis. Well, they must get it, and he anticipated that they would obtain it. $\mathrm{He}$ anticipated that they would obtain it from two sources. No thing he thought was more striking to any one who had studied educational progress in America and in our great colonies than the readiness, the eagerness, with which men who had acquired great wealth had been willing to devote a considerable portion of it in sums to which we here, he was sorry to say, were almost unaccustomed, to the promotion of the higher education. It was the case in Canada, in the great Universities of Montreal and Toronto; it was the case in America, in Cornell, in the Stamford University, in the Chicago University, in the Columbia University ; and it was also visible in the great donations which had been made to the older Universities of Harvard and of Yale. He could not doubt that the feeling that no better application than this could be found for wealth would grow among them about Birmingham, and that although they lived in a district which had hitherto not been remarkable f, t exceptional fortunes, yet which did contain many men of gre.tt wealth. They also would find a tendency, from which the University would derive advantage in the future, to make their contributions towards such purposes as he had described. $\mathrm{He}$ hoped that this might be the case, and he thought he might say that he had confidence that it would be the case, and they might expect before long that their funds would be largely increased from some such source.

\section{UNIVERSITV AND EDUCATIONAL INTELLIGENCE.}

CAMbridge.-Mr. Chawner, Master of Emmanuel College, has been re-elected Vice-Chancellor.

Mr. Frederick Harrison will deliver the Rede Lecture in the Senate House on June I2, at noon. The honorary degrees referred to last week will be conferred on the same day, at 3 p.m.

The Knightbridge Professorship is vacant by the resignation of Dr. Sidgwick, who has been seriously ill.

Mr. L. K. Wilberforce, of Trinity College, has been elected a University Lecturer in Experimental Physics in the place of Mr. W. N. Shaw.

A grant of $50 l$. from the Balfour Fund has been made to $\mathrm{Mr}$. J.S. Budgett in aid of his researches on the development of Polypterus.

Dr. Allbutt and Dr. Collingridge have been appointed delegates to represent the University at the International Congress of Hygiene and Demography to be held at Paris next August.

THE 50oth anniversary of the foundation of the University of Cracow will be celebrated to-day, June 7. Representatives will be present from most of the European universities. 